\title{
Real power loss reduction by hyena optimizer algorithm
}

Lenin Kanagasabai

Department of EEE, Prasad V. Potluri Siddhartha Institute of Technology, India

\begin{tabular}{l}
\hline Article Info \\
\hline Article history: \\
Received Jan 3, 2020 \\
Revised Mar 4, 2020 \\
Accepted Mar 23, 2020 \\
\hline
\end{tabular}

\section{Keywords:}

Hyena

Optimization

Reactive power

Real

\begin{abstract}
To solve optimal reactive power problem this paper projects Hyena Optimizer (HO) algorithm and it inspired from the behaviour of Hyena. Collaborative behaviour \& Social relationship between Hyenas is the key conception in this algorithm. Hyenas a form of carnivoran mammal \& deeds are analogous to canines in several elements of convergent evolution. Hyenas catch the prey with their teeth rather than claws - possess hardened skin feet with large, blunt, no retractable claws are adapted for running and make sharp turns. However, the hyenas' grooming, scent marking, defecating habits, mating and parental behaviour are constant with the deeds of other feliforms. Mathematical modelling is formulated for the basic attributes of Hyena. Standard IEEE 14,300 bus test systems used to analyze the performance of Hyena Optimizer (HO) algorithm. Loss has been reduced with control variables are within the limits.
\end{abstract}

This is an open access article under the CC BY-SA license.

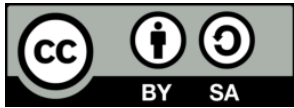

\section{Corresponding Author:}

Lenin Kanagasabai,

Department of EEE,

Prasad V. Potluri Siddhartha Institute of Technology,

Kanuru, Vijayawada, Andhra Pradesh-520007, India.

Email: gklenin@gmail.com

\section{INTRODUCTION}

Reactive power problem has been the key in power system operation \& control, since it plays major role in secure \& economic operation of the power system. Many conventional techniques [1-6] used for solving the problem. But many drawbacks have been found in the conventional methods and mainly difficulty in handling the inequality constraints. Last two decades many evolutionary algorithms [7-18] continuously applied to solve the problem. This paper projects Hyena Optimizer (HO), in which Hyena behaviour imitated to solve the problem. Collaborative behaviour \& Social relationship between Hyenas is the key conception in this algorithm [19]. Hyenas a form of carnivoran mammal \& deeds are analogous to canines in several elements of convergent evolution. Hyenas catch the prey with their teeth rather than claws - possess hardened skin feet with large, blunt, no retractable claws are adapted for running and make sharp turns. However, the hyenas' grooming, scent marking, defecating habits, mating and parental behaviour are constant with the deeds of other feliforms. Hyenas clean themselves habitually by legs are spread with one leg pointing vertically upward by sitting on the lower back. Conversely, unlike other feliforms, they do not clean their faces. Territories are built by using their anal glands. From any form of attack they defend itself ferociously and capable of producing a number of different sounds consisting of whoops, grunts, groans, lows, giggles, yells, growls, laughs and whines. Mathematical modelling is formulated for the basic attributes of Hyena. Standard IEEE 14,300 bus test systems used to analyze the performance of Hyena Optimizer (HO) algorithm. Loss has been reduced with control variables are within the limits. 


\section{PROBLEM FORMULATION}

Main aim is to minimize the system real power loss \& given as,

$$
P_{\text {loss }}=\sum_{\substack{k=1 \\ k=(i, j)}}^{n} g_{k}\left(v_{i}^{2}+v_{j}^{2}-2 v_{i} v_{j} \cos \theta_{i j}\right)
$$

Voltage deviation magnitudes (VD) is,

$\operatorname{Min}(\mathrm{VD})=\sum_{\mathrm{k}=1}^{\mathrm{nl}}\left|\mathrm{V}_{\mathrm{k}}-1.00\right|$

Load flow equality constraints:

$$
\begin{aligned}
& P_{G i}-P_{D i}-V_{i \sum_{j=1}^{n b} V_{j}}\left[\begin{array}{cc}
G_{i j} & \cos \theta_{i j} \\
+B_{i j} & \sin \theta_{i j}
\end{array}\right]=0, i=1,2 \ldots, n b \\
& Q_{G i}-Q_{D i}-V_{i \sum_{j=1}^{n b} V_{j}}\left[\begin{array}{cc}
G_{i j} & \sin \theta_{i j} \\
+B_{i j} & \cos \theta_{i j}
\end{array}\right]=0, i=1,2 \ldots, n b
\end{aligned}
$$

Inequality constraints are:

$$
\begin{aligned}
& V_{\mathrm{Gi}}^{\min } \leq \mathrm{V}_{\mathrm{Gi}} \leq \mathrm{V}_{\mathrm{Gi}}^{\max }, \mathrm{i} \in \mathrm{ng} \\
& \mathrm{V}_{\mathrm{Li}}^{\mathrm{min}} \leq \mathrm{V}_{\mathrm{Li}} \leq \mathrm{V}_{\mathrm{Li}}^{\mathrm{max}}, \mathrm{i} \in \mathrm{nl} \\
& \mathrm{Q}_{\mathrm{Ci}}^{\min } \leq \mathrm{Q}_{\mathrm{Ci}} \leq \mathrm{Q}_{\mathrm{Ci}}^{\max }, \mathrm{i} \in \mathrm{nc} \\
& \mathrm{Q}_{\mathrm{Gi}}^{\min } \leq \mathrm{Q}_{\mathrm{Gi}} \leq \mathrm{Q}_{\mathrm{Gi}}^{\max }, \mathrm{i} \in \mathrm{ng} \\
& \mathrm{T}_{\mathrm{i}}^{\min } \leq \mathrm{T}_{\mathrm{i}} \leq \mathrm{T}_{\mathrm{i}}^{\max }, \mathrm{i} \in \mathrm{nt} \\
& \mathrm{S}_{\mathrm{Li}}^{\min } \leq \mathrm{S}_{\mathrm{Li}}^{\max }, \mathrm{i} \in \mathrm{nl}
\end{aligned}
$$

\section{HYENA OPTIMIZER ALGORITHM}

Hyena optimizer (HO) algorithms imitated form Hyena which is complicated, intelligent [19]. When a new food source is found Hyena produce a typical sound alike to laughing sound of human beings to communicate about the findings. Mating between hyenas engage a number of diminutive sexual intercourse with short intervals, \& hyena cubs are born roughly fully developed, with their eyes open with adult markings, closed eyes and small ears. Hyenas do not reiterate food for their young and male hyenas play no part in lift up their cubs. For recognition they use multiple sensory procedures and have been used during he social decision making including relationships. Mathematically modelling of $\mathrm{HO}$ algorithm as follows,

Encircling prey

Mathematical model [22]of encircling the prey is;

$$
\begin{aligned}
& \vec{H}_{c}=\left|\vec{l} \cdot \vec{S}_{Q}(y)-\vec{S}(y)\right| \\
& \vec{S}(y+1)=\vec{S}_{Q}(y)-\vec{B} \cdot \vec{H}_{c}
\end{aligned}
$$

Where $\vec{H}_{c}$ - distance of Hyena with prey, $\vec{S}_{Q}$-position of prey, $\vec{S}$ - position of Hyena.

$\vec{l} \& \vec{B}$ are designed as follows:

$$
\begin{aligned}
& \vec{l}=2 \cdot r \vec{d}_{1} \\
& \vec{B}=2 \vec{c} \cdot r \vec{d}_{2}-\vec{c} \\
& \vec{c}=5.0-\left(\text { iteration } *\left(5.0 / \max _{\text {iteration }}\right)\right)
\end{aligned}
$$


Where, Iteration $=1,2,3, \ldots$, Max $_{\text {Iteration }}$

"c"- (5.00-6.00). $\mathrm{rd}_{1}, \mathrm{rd}_{2}$ are arbitrary vectors in $[0,1]$.

Hunting

The following equations are articulate the hunting procedure,

$\vec{H}_{c}=\left|\vec{l} \cdot \vec{S}_{c}-\vec{S}_{c}\right|$

$\vec{S}_{k}=\vec{S}_{c}-\vec{B} \cdot \vec{H}_{c}$

$\vec{G}_{c}=\vec{S}_{k}+\vec{S}_{k+1}+. .+\vec{S}_{K+N}$

Where $\vec{S}_{h}$ defines the position of most excellent $\&$ count calculated as:

$$
D=\text { count }_{\text {Numbers }}\left(\vec{S}_{h}, \vec{S}_{h+1}, \ldots\left(\vec{S}_{h}+\vec{E}\right)\right)
$$

Where $\vec{E}$ is an arbitrary vector in $[0.5,1]$,

Mathematical modelling of Attacking on prey

Attacking the prey has been mathematically modelled and through that vector $\mathrm{h}$ will be specified. Vector $\vec{Z}$ is varied from 5.00 to 0.00 over the course of iterations. Assigned Value $|\mathrm{Z}|<1$ will oblige \& mathematically written as follows,

$$
\vec{S}(y+1)=\frac{\vec{L}_{h}}{D}
$$

According to the position of the finest exploration agent $\vec{S}(y+1)$ will modernize the positions \& Search for prey is exploration considered in the algorithm. Hyena position in the group indicates the place in vector $\vec{L}_{h}$. In this progression of Hyena use $\vec{Z} \&$ Factor $|Z|>1$ with arbitrary values $(1,-1)$ to move away (random values which are greater than 1 or less than 1 ) which compel the search agents to move away from the prey.

Step a: Initialize Hyena population.

Step b: primary parameters are chosen.

Step c: agents (fitness value) are calculated.

Step d: In exploration space the premium search agent has been found.

Step e: group of optimal solutions defined sequentially.

Step f: modernize the positions of search agents

Step g: whether any search agent goes beyond the boundary has to be checked in the exploration space and confined to regulate it.

Step h: based on the calculation of modernized search agent fitness value, solution will be revised.

Step i: group of Hyena are modernized based on search agent fitness value.

Step j: stop criterion or else move back to Step e.

Initialize Hyena population \& parameters

Fitness of each agent calculated; While ( $<$ Maximum number of iteration) do

Modernize the agent position

End for

Modernize the parameters

Corrective action initiated if violation of search space found

Agent's fitness has been calculated

Update solution

Update the group values; $\mathrm{Y}=\mathrm{Y}+1$

End while

End

Output 


\section{SIMULATION RESULTS}

At first in standard IEEE 14 bus system the validity of the proposed Hyena Optimizer (HO) algorithm has been tested \& comparison results are presented in Table 1. Figure 1. Provide the details of Comparison of real power loss.

Table 1. Comparison results

\begin{tabular}{cccc}
\hline Control variables & ABCO [20] & IABCO [20] & Projected HO \\
\hline V1 & 1.0600 & 1.0500 & 1.0110 \\
V2 & 1.0300 & 1.0500 & 1.0120 \\
V3 & 0.9800 & 1.0300 & 1.0040 \\
V6 & 1.0500 & 1.0500 & 1.0110 \\
V8 & 1.0000 & 1.0400 & 0.9000 \\
Q9 & 0.1390 & 0.13200 & 0.10000 \\
T56 & 0.9790 & 0.96000 & 0.90000 \\
T47 & 0.9500 & 0.9500 & 0.90000 \\
T49 & 1.0140 & 1.00700 & 1.00000 \\
Ploss (MW) & 5.92892 & 5.50031 & 4.70108 \\
\hline
\end{tabular}

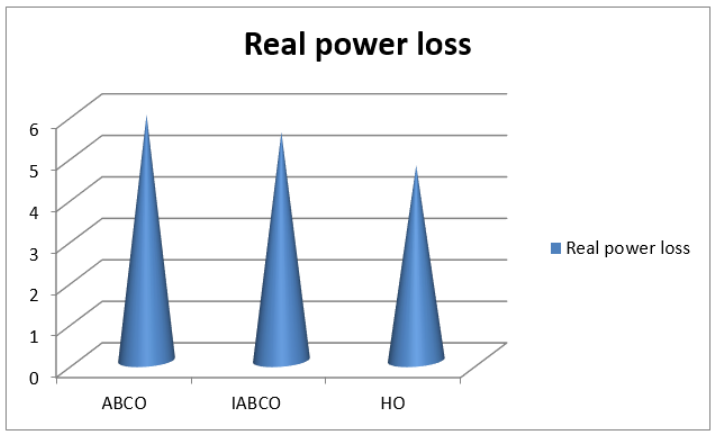

Figure 1 comparison of real power loss

Then IEEE 300 bus system [18] is used as test system to validate the performance of the Hyena Optimizer (HO) algorithm. Table 2 shows the comparison of real power loss obtained after optimization. Figure 2 gives the comparison of real power values. Real power loss has been considerably reduced when compared to the other standard reported algorithms.

Table 2. Comparison of real power loss

\begin{tabular}{ccccc}
\hline Parameter & Method EGA [21 ] & Method EEA [21] & Method CSA [22] & Projected HO \\
\hline PLOSS (MW) & 646.2998 & 650.6027 & 635.8942 & 617.8926 \\
\hline
\end{tabular}

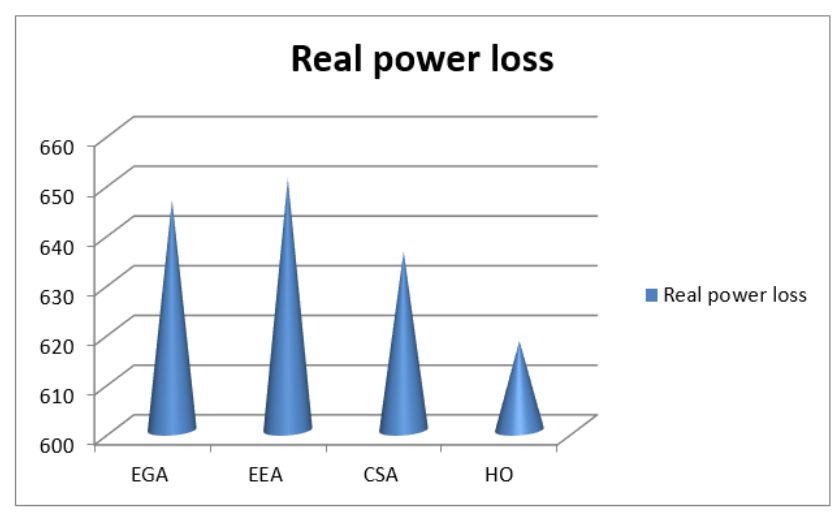

Figure 2. Real power loss comparison 


\section{CONCLUSION}

In this work Hyena Optimizer (HO) efficiently solved the reactive power problem. Deeds of the Hyena has been mathematically modelled successfully \& employed to solve the problem. Attacking the prey has been mathematically modelled and through that vector $\mathrm{h}$ will be specified. Exploration \& exploitation capabilities in the search improved. Standard IEEE 14,300 bus test systems used to analyze the performance of Hyena Optimizer (HO) algorithm. Loss has been reduced with control variables are within the limits.

\section{REFERENCES}

1. K. Y. Lee, "Fuel-cost minimisation for both real and reactive-power dispatches," Proceedings Generation, Transmission and Distribution Conference, vol, 131, no. 3, pp. 85-93, 1984.

2. N. I. Deeb, "An efficient technique for reactive power dispatch using a revised linear programming approach,” Electric Power System Research, vol, 15, no. 2, pp. 121-134, 1988.

3. M. R. Bjelogrlic, M. S. Calovic, B. S. Babic, et. al., "Application of Newton's optimal power flow in voltage/reactive power control," IEEE Trans Power System, vol. 5, no. 4, pp. 1447-1454, 1990.

4. S. Granville, "Optimal reactive dispatch through interior point methods," IEEE Transactions on Power System, vol, 9, no. 1, pp. 136-146, 1994.

5. N. Grudinin, "Reactive power optimization using successive quadratic programming method," IEEE Transactions on Power System, vol. 13, no. 4, pp. 1219-1225, 1998.

6. Wei Yan, J. Yu, D. C. Yu and K. Bhattarai, "A new optimal reactive power flow model in rectangular form and its solution by predictor corrector primal dual interior point method," IEEE Trans. Pwr. Syst., vol.21, no.1, pp. 61-67, 2006.

7. Aparajita Mukherjee, Vivekananda Mukherjee, "Solution of optimal reactive power dispatch by chaotic krill herd algorithm," IET Gener. Transm. Distrib, vol. 9, no. 15, pp. 2351-2362, 2015.

8. Hu, Z., Wang, X. \& Taylor, G. Stochastic optimal reactive power dispatch: Formulation and solution method. Electr. Power Energy Syst., vol. 32, pp. 615-621, 2010.

9. Mahaletchumi A/P Morgan, Nor Rul Hasma Abdullah, Mohd Herwan Sulaiman, Mahfuzah Mustafa and Rosdiyana Samad, "Computational intelligence technique for static VAR compensator (SVC) installation considering multi-contingencies (N-m)," ARPN Journal of Engineering and Applied Sciences, vol. 10, no. 22, 2015.

10. Mohd Herwan Sulaiman, Zuriani Mustaffa, Hamdan Daniyal, Mohd Rusllim Mohamed and Omar Aliman, "Solving optimal reactive power planning problem utilizing nature inspired computing techniques", ARPN Journal of Engineering and Applied Sciences, vol. 10, no. 21, pp. 9779-9785. 2015

11. Mohd Herwan Sulaiman, Wong Lo Ing, Zuriani Mustaffa and Mohd Rusllim Mohamed, "Grey wolf optimizer for solving economic dispatch problem with valve-loading effects," ARPN Journal of Engineering and Applied Sciences, vol. 10, no. 21, pp. 9796-9801, 2015.

12. Pandiarajan, K. \& Babulal, C. K., "Fuzzy harmony search algorithm based optimal power flow for power system security enhancement," International Journal Electric Power Energy Syst., vol. 78, pp. 72-79, 2016.

13. Mustaffa, Z., Sulaiman, M.H., Yusof, Y., Kamarulzaman, S.F., "A novel hybrid metaheuristic algorithm for short term load forecasting," International Journal of Simulation: Systems, Science and Technology, vol. 17, no. 41, pp. 6.1-6.6, 2017.

14. Sulaiman, M.H., Mustaffa, Z., Mohamed, M.R., Aliman, O., "An application of multi-verse optimizer for optimal reactive power dispatch problems," International Journal of Simulation: Systems, Science and Technology, vol. 17, no. 41, pp, 5.1-5.5, 2017.

15. Mahaletchumi A/P Morgan, Nor Rul Hasma Abdullah, Mohd Herwan Sulaiman,Mahfuzah Mustafa and Rosdiyana Samad, "Multi-objective evolutionary programming (MOEP) using mutation based on adaptive mutation operator (AMO) applied for optimal reactive power dispatch," ARPN Journal of Engineering and Applied Sciences, vol. 11, no. 14, 2016.

16. Rebecca Ng Shin Mei, Mohd Herwan Sulaiman, Zuriani Mustaffa, "ant lion optimizer for optimal reactive power dispatch solution," Journal of Electrical Systems, "Special Issue AMPE2015", pp. 68-74, 2016.

17. Mahaletchumi Morgan, Nor Rul Hasma Abdullah, Mohd Herwan Sulaiman, Mahfuzah Mustafa, Rosdiyana Samad, "Benchmark studies on optimal reactive power dispatch (ORPD) based multiobjective evolutionary programming (MOEP) using mutation based on adaptive mutation adapter (AMO) and polynomial mutation operator (PMO)," Journal of Electrical Systems, pp. 12-1, 2016. 
18. Rebecca Ng Shin Mei, Mohd Herwan Sulaiman, Zuriani Mustaffa, Hamdan Daniyal, "Optimal reactive power dispatch solution by loss minimization using moth-flame optimization technique," Applied Soft Computing, vol. 59, pp. 210-222, 2017.

19. Gaurav Dhiman, Vijay Kumar, "Spotted hyena optimizer: A novel bio-inspired based metaheuristic technique for engineering applications," Advances in Engineering Software, vol. 114, pp. 48-70, 2017.

20. Chandragupta Mauryan Kuppamuthu Sivalingam1, Subramanian Ramachandran, Purrnimaa Shiva Sakthi Rajamani, "Reactive power optimization in a power system network through metaheuristic algorithms," Turkish Journal of Electrical Engineering \& Computer Science, vol. 25, pp. 4615-4623, 2017.

21. S.S. Reddy, et al., "Faster evolutionary algorithm based optimal power flow using incremental variables," International Journal of Electrical Power \& Energy Systems, vol. 54, pp. 198-210, 2014.

22. S. Surender Reddy, "Optimal reactive power scheduling using cuckoo search algorithm," International Journal of Electrical and Computer Engineering, vol. 7, no. 5, pp. 2349-2356, 2017. 